\title{
CONFLICT-HANDLING DURING MULTINATIONAL AUDITS: THE INTERNAL AUDITOR-AUDITEE RELATIONSHIP
}

\author{
Ronja Krane
}

* Mercator School of Management, University of Duisburg-Essen, Duisburg, Germany

Contact details: Mercator School of Management, University of Duisburg-Essen, Lotharstr. 65, 47057 Duisburg, Germany

OPEN ACCESS

\begin{abstract}
How to cite this paper: Krane, R. (2019) Conflict-handling during multinational audits: The internal auditor-auditee relationship. Corporate Ownership \& Control, 16(3), 159-173.

http://doi.org/10.22495/cocvl6i3art13

Copyright $@ 2019$ The Authors
\end{abstract}

This work is licensed under a Creative Commons Attribution 4.0 International License (CC BY 4.0).

https://creativecommons.org/licenses/by/ $4.0 /$

ISSN Online: 1810-3057

ISSN Print: 1727-9232

Received: 09.04 .2019

Accepted: 11.06.2019

JEL Classification: M16, M42 DOI: $10.22495 /$ cocvl6i3art13

\begin{abstract}
As companies expand their operations across national borders, international internal audit assignments are becoming commonplace. However, the internal audit functions of multinational companies face unique issues since their work quality is influenced by interactions with employees from various locations and culturally diverse backgrounds. The aim of this paper is to analyze these interactions. For this purpose, fourteen qualitative in-depth interviews with internal audit practitioners working for globally operating companies are conducted. Qualitative content analysis is used to structure and analyze the interview data and results are presented within a conceptual framework based on Resource Dependence Theory and insights from conflict theory. The study examines the conflict-handling strategies that are employed during the distinct stages of crossnational internal audit assignments and sheds light on how internal auditors achieve their audit related goals while interacting with auditees of different cultural and linguistic backgrounds. Findings indicate that internal auditors are partly reliant on the knowledge and cooperation of auditees, and conflicts need to be handled in a manner which allows the internal audit function to obtain the necessary resources. Overall, results show that country and culture-specific differences can cause or complicate conflict situations and auditors are tasked with finding the difficult balance between trust and skepticism towards auditees when conducting cross-corporate audit assignments. This paper contributes to the scarce literature on the relationships between internal auditors and auditees and expands the current understanding of internal audit work in an international context.
\end{abstract}

Keywords: Internal Audit, International Context, Auditor-Auditee Relationship, Conflict

Acknowledgment: I acknowledge support by the Open Access Publication Fund of the University of Duisburg-Essen. I am thankful to participants of the EARNet 2017 Ph.D. Workshop in Leuven, Belgium, the AAA Auditing Section Midyear Meeting 2018 in Portland, USA and the 8th Doctoral Seminar of the Universities FU Berlin, TU Darmstadt, Duisburg-Essen, Hamburg and Ulm in Duisburg, Germany for their helpful comments and suggestions on earlier versions of this paper.

\section{INTRODUCTION}

The internal audit function (IAF) is responsible for providing objective and independent assurance and consulting services to the entire organization. This requires many auditors of multinational companies to regularly conduct international audit assignments, which, apart from being conducted in a non-native language, involve cultural aspects that can easily complicate the often already tense relationship between auditor and auditee 
(Woodworth \& Said, 1996). Cultural differences are not automatically disappearing even though connections between countries and the internationalization of companies are increasing (House, 2004). In accordance with Dittenhofer et al. (2010, p. 11) who call internal auditing a "relationship and communications business", the purpose of this study is to provide detailed insights into the experiences of internal auditors interacting with auditees from various national and cultural backgrounds in the context of conducting crosscorporate audits. The issue of auditor-auditee conflicts in this context is important because worldwide audit assignments are part of many auditors' work routines, and IAFs of multinational companies face some unique issues as their work quality is influenced by interactions with company employees at these diverse locations. This is of interest not least because external auditors will potentially rely on the IAF's work. The way auditors perform their duties and achieve their audit related goals while having to face and resolve conflicts with auditees of different nationalities, cultures, and languages has not been adequately researched. This study was conducted in cooperation with the German national chapter of the Institute of Internal Auditors (IIA) as a result of the continuing dissatisfaction among internal audit practitioners about a lack of benchmarks concerning international audit assignments. The analysis aims to explore the peculiarities and challenges auditors face during such engagements and to document the strategies auditors employ to ensure audit success while interacting with auditees across the globe.

In-depth interviews and qualitative content analysis are used to investigate conflicts between internal auditors and auditees in multicultural, multinational working environments. The purpose, as well as the result, of employing different conflicthandling styles is investigated to allow for a characterization of auditor-auditee interactions in globally operating companies. Fourteen interviews were conducted with 24 practicing internal auditors who provide an important window into how the IAF deals with such international audit assignments. These auditors work for companies of varying sizes that operate internationally and cover a broad range of industries. The interviews were transcribed and systematically analyzed using qualitative content analysis which follows rules and theory and places a special emphasis on context (Mayring, 2000, 2014). Interactions of auditors and auditees are categorized and findings are interpreted using a conceptual framework. The conceptual analysis framework is based on Resource Dependence Theory (Pfeffer \& Salancik, 1978) as well as insights from conflict theory. The five conflict-handling modes by Thomas and Kilmann (1974) are used to structure and analyze interactions between internal auditors and auditees. Furthermore, the analysis considers the International Professional Practices Framework (IPPF), formulated by the IIA (2016), which includes the International Standards for the Professional Practice of Internal Auditing as well as the Core Principles.

Findings indicate that internal auditors are partly reliant on the knowledge and cooperation of auditees and are tasked with striking a balance between trust and skepticism towards auditees when conducting audit assignments in multinational companies. While most audits bear a high potential for conflict due to the opposing interests and goals of the parties involved, this study finds evidence that national, cultural and linguistic differences can cause or further aggravate conflicts between auditors and auditees. In order to obtain the information needed for a successful audit, auditors, therefore, have to adjust their conflict-handling style while dealing with possible country-specific uncertainties and knowledge gaps. While avoiding conflict is not a viable option for members of the IAF, they employ more or less cooperative and assertive behavior to achieve their goals of obtaining information while also trying to foster a positive working environment. Findings indicate that intracompany networks, third-party support as well as a strong corporate culture facilitate auditorauditee interactions in an international context.

This study contributes to the limited literature on the relationship between internal auditors and auditees in several important ways. First, prior works, with the exception of D'Onza and Sarens (2018), have often provided only general recommendations on establishing and managing auditor-auditee relationships. In his literature review, Smith (2005) highlights the importance of internal auditors possessing advanced communication skills as well as their understanding of communicational processes and different communicational levels. Loss (2000) states that auditors should communicate in a clear, timely, open and unbiased manner, listen to auditees' concerns and adequately address them, while Allen (1996) offers general guidelines on dealing with conflicts between auditors and auditees. Secondly, while Roussy $(2013,2015)$ analyzes how internal auditors perceive, express and manage role conflicts in their work based on interview data collected from internal auditors working in public-sector organizations, this study's sample features internal auditors working for a broad variety of globally operating private-sector companies in different industries. Moreover, and most importantly, there is limited prior research on the interaction of internal auditors and auditees in an international and crosscultural context, even though such potentially complex engagements are a part of many auditors' work realities. Woodworth and Said (1996) conduct survey-based research on the impact of auditees' nationalities and cultural background on SaudiArabian auditors' perception and experiences with them. However, their quantitative study does not provide insights into the specific conflict situations and conflict-handling styles of auditors and auditees in the international context.

This study seeks to address the research gap on such auditor-auditee interactions and to add to the audit literature by exploring the unique context in which the IAF of a global company operates. Therefore, the following research question is posed:

How do internal auditors and their auditees handle conflicts that arise before, during and after cross-national audit assignments?

The remainder of the paper is organized as follows: A literature review is provided in Section 2. The conceptual framework is introduced in Section 3. Section 4 addresses the research method while Section 5 presents the study's results. Section 6 contains the discussion and conclusion of the paper. 


\section{LITERATURE REVIEW}

Studies with a focus on external auditors have found that the interactions between auditors and auditees can have an impact on the audit engagement's success. Sweeney and Pierce (2011) show that the auditees' approachability is strongly influenced by their assessment of the external auditor's personality, skills, and judgements. Guénin-Paracini et al. (2015) find that auditees' cooperation is a key to a smoothly conducted audit while also observing a number of strategies that external auditors use to obtain information should auditees display uncooperative behavior. However, studies on the interaction between external auditors and auditees might have limited explanatory power for the communication of internal auditors and auditees. A study by Burt (2016) presents evidence that the external auditor-auditee relationship differs from the one between internal auditors and auditees since internal auditors can fulfill the role of a trusted insider and auditees might be more willing to share certain information with them than they are to share it with someone external. Pickett $(2007,2010)$, on the other hand, comments on possible differences by noting that internal auditors do not have the same incentives as external auditors to provide client service and that instead of focusing on positive auditor-auditee interactions they might adopt the role of policemen within the organization.

To this day, the relationships and interactions of internal auditors and auditees have been underexamined, even though they can potentially influence the IAF's effectiveness (D'Onza \& Sarens, 2018). Communication, listening, and influencing skills are a requirement for internal audit fieldwork and interactions with auditees in the organizational setting (Chambers, 2008). Lenz et al. (2017) find that being good at dealing with people and establishing relationships are crucial skills for a successful internal auditor while Ma'ayan and Carmeli (2016, p. 351) see the management of auditor-auditee interactions "in a way that suppresses negativity and cultivates the auditees' positive attitude toward the audit process" as the key to motivating auditees to engage with the IAF and to improve.

While a research report by the IIA finds that the auditor's ability to contribute to the overall organizational goals is limited by auditees unfavorable attitudes towards the IAF (Mints, 1972) and, more recently, Fanning and Piercey (2014) find that the internal auditor's likability is a factor which influences managers' judgements, relatively little research has been conducted on internal auditors' interpersonal relationships with the audited entities' staff and management despite the importance of the topic (Archambeault et al., 2008; Prawitt et al., 2009). Furthermore, little is known about the role internal auditors assume while performing their work (Roussy, 2013). Skinner and Spira (2003, p. 28) stress that "a better understanding of the complex dynamics of the interpersonal relationships which underpin control mechanisms is necessary if the effectiveness of governance systems and procedures is to be increased" and a call for more research on internal auditing is echoed by Archambeault et al (2008), Prawitt et al. (2009), Burton et al. (2012), Fanning and Piercey (2014), and Lenz and Hahn (2015).
Internal auditors are tasked with exercising sound judgements in often challenging situations and their respective decisions can impact entire organizations as well as the individuals within those organizations (Larkin, 2000). In this context, the specific role and function of the internal auditor in the company, as well as the differing nationalities of auditor and auditee, are possible influences on the auditor-auditee relationship which bear enormous potential for conflicts between both parties. Since auditors use their right to information, ${ }^{40}$ among other things, for uncovering mistakes, weaknesses or inefficiencies in operational departments they might be viewed critically, and fear or distrust can complicate or prevent open communication with the audited entity (Mints, 1972; Funnell \& Wade, 2012). On the other hand, internal auditors might be recognized as members of the same organization and fulfill the role of a trusted insider in whom auditees can confide (Burt, 2016). D'Onza and Sarens (2018) conclude that high-quality relationships between internal auditors and auditees are associated with the use of the IAF as a management training ground as well as with the input given by senior management while setting up audit plans. However, an IAF that conducts a high number of different activities can hinder positive relationships with auditees. A number of studies also highlight the demands that auditees place on the IAF. Wealleans (2005) establishes that the IAF is considered effective in the eyes of auditees only when suggested measures are non-trivial, while Anderson (2003) states that internal audit adds value for its auditees when cost savings, process efficiency or operations effectiveness are increased by the auditors' recommendations. Furthermore, a study by Elliott et al. (2007) suggests that auditees do not consider the IAF to add value when they fail to analyze root causes of the existing problems or make low-quality suggestions for improvements.

Moreover, potential conflicts of interest between the internal auditor and the auditee which may lead to disputes between the two parties cannot be ruled out (D’Onza \& Sarens, 2018). Conflicts may also arise since there is a persisting information asymmetry between auditors and auditees, which can be exploited by auditees (Choi et al., 2010). Since auditors often rely on the auditees' support for improving the company's internal control, risk management, and governance systems, managing relationships with auditees can be of crucial importance for the IAF (D'Onza \& Sarens, 2018). If an auditee is reluctant or refusing to cooperate, this behavior can impede the IAF's effectiveness (Dittenhofer, 2001) which will possibly harm not only the company itself but also the auditor-auditee relationship.

Cultural differences are another factor that potentially affects the auditor-auditee relationship and creates the potential for conflict since a person's culture influences the way in which he or she reacts to specific events or situations (Woodworth \& Said, 1996), e.g., being confronted with the auditor's probing questions. The cultural dimension thus adds to the often tense auditor-

\footnotetext{
${ }^{40}$ In its Model Internal Audit Activity Charter the IIA suggests authorizing the IAF with "full, free, and unrestricted access to any and all of [the organization's] records, physical properties, and personnel pertinent to organization's] records, physical properties, ar 
auditee relationship. According to Schein (2010) culture is made up of shared, implicit assumptions that a group has learned in order to cope with external tasks and while dealing with internal relationships. Culture, therefore, consists of invisible elements that are difficult to define and measure, ${ }^{41}$ which can further complicate the already complex auditor-auditee relationship.

\section{CONCEPTUAL FRAMEWORK}

This paper uses a theoretical bricolage to explore auditor-auditee conflict in multinational companies Rather than developing a new theory, a theoretical lens or framework, made up of a number of concepts from existing theories, is constructed (Boxenbaum \& Rouleau, 2011; Gendron, 2013; Roussy, 2015) and used to study conflicts between internal auditors and auditees in the international context. This paper's conceptual framework is based on Resource Dependence Theory (RDT) (Pfeffer \& Salancik, 1978) and insights from the conflict theory literature.

\subsection{Resource dependence theory}

Resource dependence is the extent to which an organization is dependent on the resources which are controlled by one or more nominally independent parties in the organization's environment (Pfeffer \& Salancik, 1978). Information and know-how can be considered resources in the same way as raw materials or labor force. RDT assumes that being dependent on resources influences the organization's actions and can thus help to explain its behavior.

The application of RDT to the auditing context is in line with Cohen et al. (2008, p. 181) who suggest its use "to provide a more comprehensive view of corporate governance than that considered by the traditional agency literature". For this purpose, this study considers the IAF and the audited entities to be nominally independent parties since auditors generally have no authority to issue directives to auditees. Furthermore, the IAF is considered, in varying degrees, to be resource dependent on the audited entity (Dittenhofer (2001), as well as D'Onza and Sarens (2018), reflect on this idea to some extent). In order to audit efficiently and effectively, auditors may be reliant on the auditees' knowledge about the day-to-day business, about processes and problems, and, especially in a multinational context, on their knowledge of legislation, local customs, and languages. This dependency reduces the IAF's autonomy. The dependent party will strive to restructure and reduce resource dependencies or to gain legitimacy to stabilize relationships (Pfeffer \& Salancik, 1978). However, according to RDT, the party which controls critical resources holds a certain amount of power over those who are resource dependent, which is why scarce resources will often lead to power games and conflicts.

\footnotetext{
${ }^{41}$ Hofstede (2001) suggests five dimensions which enable the comparison of Hofstede (2001) suggests five dimensions which enable the comparison of
distinct cultures, namely: power distance, uncertainty avoidance, distinct cultures, namely: power distance, uncertainty avoidance,
individualism/collectivism, masculinity/femininity, and long-term/short-term orientation. However, cultural standards can never capture the behavior of each person belonging to a cultural community, e.g., a nation, and instead describe the cultural normalcy expectation from which an individual's orientation can differ greatly (Lüsebrink, 2012).
}

\subsection{Conflict theory and conflict-handling styles}

Within their organizations, internal audit practitioners are often faced with possible conflicts (Reynolds, 2000). Conflict can be defined as "an interactive process manifested in incompatibility, disagreement, or difference within or between social entities i.e., individual, group, organization, etc." (Rahim, 1992, p. 370). Conflicts between internal auditors and auditees may be the result of the power dynamics resulting from resource dependence. Woodworth and Said (1996) assume that conflicts arise while the internal auditors are searching for information or evidence and auditees do not provide the requested details or give disingenuous answers. However, while some auditees may try to hide existing problems, many conflicts are likely to be caused by misunderstandings which in turn arise due to cultural differences between the parties. According to Woodworth and Said (1996), there can also be a possible resentment on the auditee's part because their work routine is interrupted by the IAF and their job might be dependent on the audit outcome. To date, disagreements about goals have been the primary focus in conflict research, even though conflict may also arise when goals are shared but opinions about the appropriate means of achieving an end, meaning the actions to be taken, differ (McGrath, 1984). It can be assumed that both auditor and auditee share the overarching goal of enterprise survival. However, while auditors might feel that they best contribute to the company's survival by interrupting the auditee's work to make further inquiries, the auditee's course of action may be to be productive and continue with his/her operational duties. Goals are the motivating force behind any action and can shape or constrain as well as provide explanations for occurring interactions (Dillard et al., 1989). Obtaining material and nonmaterial resources, such as information or relational resources in the form of valued relational assets like trust or personal resources, which include temporal assets, is assumed to be a major concern for auditors. The goal of an internal auditor will often be to gain assistance from auditees. Gaining assistance in this context describes the obtaining of information which is needed to provide risk-based assurance and promote organizational improvement.

Conflicts during international audit assignments can, therefore, arise due to a variety of factors: different linguistic and cultural backgrounds, a lack of familiarity among both parties, prejudices, misconceptions about the goals of the other party or even due to the type and phase of a specific audit which can cause high or low amounts of stress, e.g. ad hoc or surprise audits vs. scheduled audits. It should be noted that each conflict contains a message which often carries overt and/or implicit information about the interaction and relationship of both parties (Watzlawick et al., 1967; Folger \& Poole, 1984).

Thomas and Kilmann (1974) established five distinct styles of conflict-handling which are determined by the dimensions of assertiveness and cooperativeness ${ }^{42}$ as summarized in Table 1 .

\footnotetext{
42 Thomas and Kilmann's work follows that of Blake and Mouton (1964) who developed the managerial grid. Rahim and Bonoma (1979) developed a who developed the managerial grid. Rahim and Bonoma (1979) developed a
} similar framework which organizes the five conflict-handling styles along the 
Table 1. Assertiveness and cooperativeness of conflict-handling modes

\begin{tabular}{|l|c|c|}
\hline $\begin{array}{c}\text { Conflict-handling } \\
\text { mode }\end{array}$ & Assertiveness & Cooperativeness \\
\hline Competing & High & Low \\
\hline Collaborating & High & High \\
\hline Compromising & Intermediate & Intermediate \\
\hline Avoiding & Low & Low \\
\hline Accommodating & Low & High \\
\hline
\end{tabular}

Source: Thomas and Kilmann $(1974,2008)$

The five conflict-handling modes of the Thomas-Kilmann Conflict Mode Instrument form the categories used for the qualitative content analysis. Structuring and classifying the interactions of internal auditors and auditees in this way allows for an investigation of the interactions between both parties and illustrates the various strategies auditors and auditees use for handling conflict before, during and after an audit engagement. The conflicthandling modes are described by Thomas and Kilmann (2008) as: 1) Competing, which means a person is pursuing his or her own goals and displaying assertive and uncooperative behavior; 2) Collaborating that describes working with others to find a solution that satisfies both parties and can be classified as assertive and cooperative behavior; 3) Compromising, where an individual is aiming to find a solution which is mutually acceptable and partially satisfies all parties involved. This can be considered as behavior that is intermediate on the assertiveness as well as the cooperativeness dimension; 4) Avoiding, which describes individuals that are not pursuing their own or other people's concerns and are therefore not addressing conflict, meaning they exhibit unassertive and uncooperative behavior; 5) Accommodating, which encompasses the behavior of people who disregard their own concerns and instead focus on satisfying the concerns of the other party, meaning they display cooperative and unassertive behavior.

\section{RESEARCH METHOD}

Qualitative research methods have the ability to bring forth an enormous amount of detailed information by studying a limited number of cases (Patton, 1990). The aim of constructive research is to inform and improve practice (Lincoln et al., 2011) through the analyses of complex human behavior and an in-depth understanding of the subject (Power \& Gendron, 2015). The focus on describing and understanding processes through the means of conducting in-depth interviews and employing qualitative analysis allows an examination of "the meanings individuals bring to the processes in reallife organizational settings" (O'Dwyer, 2011, p. 1238-1239) and to gain a deep understanding of what it means for internal auditors to take on international audit assignments. By interviewing practicing internal auditors, this study is able "to tap into the knowledge of those who have the requisite experience, first-hand knowledge, and understanding to provide meaningful insight" (Malsch \& Salterio, 2016, p. 6).

\subsection{Data collection}

Consistent with Cohen et al. (2010) and Beasley et al. (2009), a semi-structured interview approach was used to address the research question and to gain insights which could not have been attained using archival methods. For this study, fourteen semistructured interviews were conducted. ${ }^{43}$ Four interviews took place with one interviewee; the other ten interviews were conducted in a setting with two participants from the same company present. ${ }^{44}$ Of the total of 24 participants, seven were female, seventeen were male. ${ }^{45}$ Interviewees were between the ages of 25 and 55 and held the position of either Chief Audit Executive or staff level auditor. The sample is made up of a diverse group of auditors who not only have significant knowledge of the IAF and its tasks but who are also directly involved in the planning, implementation or execution of international internal audit assignments. These individuals were chosen in order to capture a crosssection of internal auditing experience, industries, and company size. Auditors belong to fourteen German multinational companies (six of which belong to the DAX-30 companies and two of which are members of the MDAX) that are operating internationally in a variety of industries such as the manufacturing sector, logistics, transport industry, finance, service, real estate management, and foodstuff industry. The companies have annual revenues between $€ 1.1$ and $€ 213.3$ billion and employ between 2,000 and 500,000 people. The interviewees were recruited through personal contacts of IIA members which helped to ensure a trusting relationship and relaxed atmosphere during the interview process.

The interview guide was developed in close collaboration with internal audit practitioners. Additional questions were added to the interview guide based on academic literature related to internal auditing as well as based on emerging themes from the first couple of interviews. Following Hirst and Koonce (1996, p. 460), "when questions took us down an important path, we pursued them before returning to the planned interview material". Interviews were conducted as part of a broader data collection process between March and July of 2016 and lasted on average 53 Minutes. All interviews were conducted by the same person either in the participants' offices or in the interviewer's office, with the exception of two interviews that were conducted by telephone. In eleven cases permission was obtained to tape record the interviews in

43 The point of saturation was reached after thirteen interviews. This is consistent with Guest et al. (2006) who find that twelve interviews are
sufficient for studies aimed at identifying common experiences and perceptions among groups of individuals. Nevertheless, the remaining perceptions among groups of individuals. Nevertheless, the remaining already been made.

44 Advantages of joint interviewing lie in the possibility of revealing different kinds of knowledge held by the interviewees and aiding to produce more (Seymour data since participants can supplement gaps in the others memory (Sn atmosphere of confidence (Edgell, 1980).

45 It should be noted that the present study aims to capture the breadth of It should be noted that the present study aims to capture the breadth of
conflict-handling as employed and experienced by internal auditors and
therefore no distinct focus is placed on comparing and contrasting one therefore no distinct focus is placed on comparing and contrasting one specific group of auditors to another. While it is possible that gender diversity exerts a certain influence on conflict-handling styles, for example, when making decisions female directors have been found to be more likely to use a cooperative approach (Bart \& McQueen, 2013), no discernible differences based on the auditors gender could be observed in our data. Thus, in the

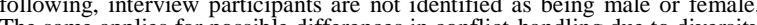
The same applies for possible differences in conflict-honding due to diversity in participaps' ages, hierarc the area is encouraged. 
addition to taking extensive notes. The recordings were later transcribed verbatim. ${ }^{46}$

\subsection{Data analysis}

This paper uses Mayring's qualitative content analysis in order to systematically analyze the transcripts and arrive at conclusions about particular aspects of communication while following rules and theory (Mayring, 2000, 2014). The analysis considers the context and the latent meanings of what is said because the meaning of text units changes according to the context and can therefore not be fixed lexically or objectively.

Structuring is used to extract and summarize certain topics, themes and aspects from the data through a category system. Structuring allows the organization of the text according to empirically and theoretically meaningful perspectives and subsequently enables a structured description of the collected data (Mayring, 2014). Furthermore, the category system aids in providing transparency for the reader by making the research method traceable. The relevant content was structured into five categories of different conflict-handling styles to illustrate the challenges auditors face when auditing internationally and to examine the strategies and tools used to handle conflict. Deductive category application was used by which categories were derived from the literature on conflict theory, specifically from the Thomas-Kilmann Conflict Mode Instrument. The "methodological controlled assignment of the category to a passage of text" (Mayring, 2000, p. 4) forms the qualitative step of the content analysis.

The relative openness of Mayring's analysis furthermore allows for inductively deriving information from the data to alter the categories derived from theory. The scope of each category can, therefore, be adjusted to the specific, international audit context. Following Barrett et al. $(2005$, p. 2) the analysis "is not intended to celebrate the empirical detail", but instead to gain insight into the many facets of internal auditors' and auditees' interactions, the challenges and conflicts they face over the course of an international audit assignment, how auditors deal with these conflicts, and what can be learned from this about the auditor-auditee relationship.

\subsection{Credibility}

Prior to the interview, a copy of the questions was sent to the participants and the study's purpose was described at the beginning of each interview. A nondisclosure agreement was signed by the interviewer to assure the participant that they and the companies they work for would remain anonymous and that all obtained data would be treated with absolute discretion. For this purpose, all details that could enable a reader to draw conclusions about the identity of a company were generalized or omitted from the text. Alphanumeric codes were assigned to each interviewee which enable quotes to be traced back to the respective speaker and shows they stem from many different interviewees while still providing anonymity. The first two digits denote the

\footnotetext{
46 All interviews were conducted in German. The quotes reported in this paper were translated into English.
}

company interviewees belong to. The last letter enables a distinction between two auditors from the same company.

Following Lincoln and Guba (1985), to increase credibility, interviews were conducted with auditors from a broad range of companies, allowing for many possible representations of the internal auditors' reality to emerge. Member checking was used to further improve the results' credibility and the study's overall reliability. First, over the course of each interview, the interviewer would verbally summarize and paraphrase certain statements made by the participants in order to prevent misunderstandings and misinterpretation of what was said. Secondly, preliminary findings of the interviews were presented to the participants, who were given the chance to discuss, question and respond to results. The presented data met with the participants' approval. Through these measures, it can be assured that the study captured the responses of the participants with a high degree of accuracy.

\section{RESULTS}

Consistent with Roussy (2015), results will be discussed by roughly following the timeline of an audit engagement as outlined in the IPPF's standards, starting with audit preparations, to the on-site fieldwork, to the composition and distribution of the audit report and dealing with negative consequences of audit findings during the post-audit phase. In doing so, the various potential conflict situations become apparent while strategies and tools to resolve conflicts can be highlighted.

\subsection{Audit preparation and resource management}

According to IIA standard 2010 - Planning, the audit plan must be aligned with the organization's objectives and audit planning should take the IAF's stakeholders' expectations into account. As the IAF's available manpower and overall budget are limited, resource management is crucial at this initial stage of preparing the audit, which is especially true in the international context, where audits can incur significant travel time and costs.

Competing: "First, we say that not everyone can demand an audit, instead there is a very structured process, ... they need to go to the highest position in their organization and then they need to officially knock on my door .... If it makes sense [to do the audit] we will approve and it will then be decided [in Germany], not locally, deliberately not locally, instead exclusively [in Germany]." (13A)

The process that would lead to the adjustment of the already established audit plan follows a clearly established protocol. The IAF pursues its own concerns at what can be seen at the expense of the potential auditees' wishes. Foreign entities need to clear a set of hurdles before they can bring their request before the CAE in Germany who reserves the right to make the final decision on if and when an audit will take place. Through these set paths of communication, the IAF at the company's headquarters can enforce its right and obligation to develop and follow a risk-based audit plan while at the same time being mindful of its available resources and saving valuable time and money by only engaging with select audit requests. However, 
the actions taken by the IAF following an audit request depend largely on the IAF's assessment of such requests.

Compromising: "The first question is always: Do they want a free pass and what for? So, sometimes there is this tendency that they will try to delegate the responsibility for regularity back to us and there you have to be a little careful. Of course, you can give them a piece of advice, of course, you can assess something, but you have to be very vigilant whether they don't just want a signature to later be able to say 'this has been agreed upon with Internal Audit'." (03B)

The auditor displays willingness to compromise, meaning they are looking for a way to satisfy both the auditee as well as the IAF's concerns. While giving advice and providing support, they are at the same time acutely aware that entities might try to use audit results for their own agenda. Participants also noted that regional managers would sometimes ask auditors to issue memos or other documents in order to strengthen the person's own position. Internal auditors handle such conflicts by competing, which makes it clear that the IAF is in charge of audit planning, or by compromising. Compromising can indicate a certain distrust of the motivation behind the audit request. However, auditees are considered to belong to the group of IAF stakeholders (D'Onza \& Sarens, 2018) and if auditors believe the foreign entities to be sincere in asking for the IAF's support, audit requests should be addressed accordingly and can even be seen as an indicator of trust towards the IAF.

The resources of the IAF have to be "appropriate, sufficient, and effectively deployed to achieve the approved plan" according to standard 2030 - Resource Management. The composition of any given audit team needs to take this into account by assigning audit engagements to auditors with the appropriate characteristics and competencies. The IAF's goal is to provide assurance and advice, thus, auditors have to possess the skills and knowledge needed for a specific audit engagement. Apart from the obvious requirements for specialist knowledge, country and culture-specific characteristics are considered when making staffing decisions for international audit assignments:

Accommodating: "The team obviously has to be composed accordingly. When we are in the Arabic world, for sure a woman can't take on the head auditor position. ... As a cultural approach I find this important, it's also part of our code of conduct, to take into account the local conditions and treat them with appreciation." (02A)

A female head auditor might be a problematic choice in certain cultures. The IAF accepts this and even encourages the accommodation of specific needs through their code of conduct. Potential conflicts are thus handled by satisfying the concerns of the audited entity rather than doing what might be most convenient for the IAF.

Accommodating: "Of course, there are some things we pay attention to, ... to send a Japanese head auditor to China could be problematic .... So instead you would give him a normal auditor role and take someone from China or from Europe [as the head auditor]." (01B)

The Japanese occupation of China could still be a point of contentment between the two nations, thus, assigning a Japanese auditor to lead an audit in
China could be perceived as a provocation. By being courteous and considerate when making staffing decisions the IAF can maintain their relationship with the audited entities and help to ensure a smooth audit process. Auditors are aware that both culture and history can influence interpersonal interaction, create conflict and impede the IAF in achieving their resource-related goals of obtaining necessary information.

\subsection{Fieldwork on-site}

Upon arriving on the site of the audit, auditors are confronted with the foreign entities' attitudes towards the IAF. A lack of information or preexisting misconceptions about internal auditing as well as cultural characteristics and personal experiences can cause a range of reactions from the auditees. Having been audited in the past was seen as helpful because it meant auditees knew what to expect and were not fearful of the internal auditors. This further supports the importance of relational resources and the establishment of a positive relationship. Firsttime auditees, on the other hand, will often exhibit challenging behavior, such as competing by being uncooperative and trying to establish dominance over auditors:

Competing: "Well, I know that in Russia they took bets on whether my audit colleague was 20 years old already or not. So there are some things like that." (04B)

While other auditees aim to avoid a possible conflict situation all together:

Avoiding: "There are differences also between the hierarchical levels, so the management is relatively relaxed but for example, if you're talking to a normal employee in China, they will dodge [the auditors], because they maybe don't understand it, even if you're friendly." (06B)

The auditor also mentions the Chinese being very hierarchical, so a staff-level employee might not be accustomed to interacting with anyone from the company headquarters. Auditees might be shy or even scared or simply feeling like it is not their responsibility to talk to internal auditing.

However, many of the interviewed auditors feel they have a certain standing among auditees because they come from what is either the head audit office or a centralized audit office at the company's headquarters. Auditors report auditees standing at attention and their awareness being heightened simply because someone from the company's headquarters will be auditing them.

Accommodating: "In Saudi-Arabia, also in Africa, I would say, it's the same situation. You do get the impression that 'someone from the centralized IAF is coming' so answers, as well as files that you request, will be made available to you relatively quickly. So they do take the issue seriously." (05B)

Heightened alertness can be desirable if it leads to compliance with and prioritization of audit work which facilitates the obtainment of informational resources for the IAF. Instead of engaging in power games, auditees are being cooperative and honor the auditors' requests. The auditor's connections and position within the company can facilitate audit work in other ways as well. Being able to rely on a network within the company can also help to mitigate conflict. 
Collaborating: "Something that helps us enormously with the audits is that we always have expats as a contact person, or for the most part we find expats in our external organization who we contact and that will tell us 'well, you need to watch out for this and that, be careful here with your communication'. This really pays off." (05B)

Auditors use a middle-man to enable them to identify underlying concerns and learn about behavior $s$ that could potentially complicate interactions with the auditees. Auditors will often adjust their actions accordingly and display collaborative behavior by attempting to find an audit approach that satisfies the concerns of both parties. By contacting an expatriate who lives and works abroad auditors gain access to the knowledge of someone who has the same cultural background as them but who is also familiar with the mindset and cultural characteristics of the foreign entity and can thus identify potential sources of conflict between auditors and auditees beforehand. The same auditor notes that it also works the other way around, where the local managers set the tone at the top and convey information about the visiting auditors to the auditees which can serve to dispel possible fear or distrust of the IAF.

Another key factor which encourages cooperative conflict-handling styles is the personal attributes of the auditors. A similar background or a uniformity of mindsets can shape the auditees' attitude towards any auditor and influences the interaction between both parties during an audit.

Collaborating: "The auditors, they are all people who come from the same stable, they all smell of the same stable, they are not perceived as some sort of know-it-all from the outside, instead they are all perceived as people with whom you can work on eye level." (10A)

A sense of similarity because of a shared background or uniform attitude towards the company can cause auditees to see auditors more as colleagues and equals than as competitors and outsiders, which in turn will support their resource goals. Internal auditors, who in this case are recruited from inside the company, fulfill the role of trusted insiders as described by Burt (2016). They are accepted by the audited entities which cooperate with them because of the auditors' company-specific knowledge, skill sets, and experiences. Belonging to the same company can be a powerful asset in facilitating interactions between employees from different departments and countries if the respective corporate culture is conducive to a uniform mindset and a sense of belonging. A number of interviewees specifically mentioned a strong sense of community which seemed to overwrite potential differences between auditors and auditees and encouraged cooperative behavior.

Collaborating: "You really shouldn't underestimate this pull, this magical, almost magical, effect of the [company-] family. So, it doesn't matter where you go, there is a really, really, really tight bond of the employees." (05A)

Shared corporate culture seems to be able to offset possible conflicts arising from cultural differences as well as from different job profiles of auditors and non-auditors. The tone at the top of the audited entity as well as past experiences with an internal audit are additional factors which determine the emergence and handling of conflict situations.
One auditor reported that the IAF was very visible for the management of the foreign subsidiaries since internal audit topics are addressed during an annual corporate exchange where the subsidiary's management is present. Addressing internal audit topics during a regularly scheduled management meeting can serve to improve the relationship between foreign entities and auditors from the centralized head audit office. The foreign management interacts with auditors outside of the typical audit setting in a situation that bears less potential for conflict than, e.g., the presentation of recent audit findings. Additionally, including internal auditors in a management meeting can serve as a signal to the foreign entities that the IAF is highly valued and deemed important by the executive board. The foreign management can then, in turn, influence their staff's opinion of the IAF prior to the auditors arriving on-site.

At times the first contact between auditor and auditee will take place in the form of a kick-off meeting during which the auditors introduce themselves and explain the audit objectives.

Compromising: "During the kick-off meeting everyone will say 'oh internal audit is here' but in the end it probably depends on the auditor, how you present yourself and that you don't act like a policeman, instead tell them from the start: 'Listen, we are colleagues, we work for the same company. You have your job, I have my job. Maybe your job is controlling, my job is an internal audit. Don't worry. I'm not interested in your position, I'm interested in the company, it's about money, it's about your money, it's about my money. If there is an added value for the company then we all benefit from it."” (08A)

This auditor uses the first meeting on-site to position himself/herself as a colleague to the auditees and to stress a common goal. Being aware of the potential for conflict and auditees' possible concerns towards the IAF means he/she uses this opportunity to defuse a threating situation and clarify what the auditor's role in the company entails and what the objectives are. The aim is to change the auditees' perception of the IAF by stressing the company as the common denominator. The auditor is compromising by searching for a middle ground and an expedient solution which is acceptable for both the IAF and the audited entity. While not being overly accommodating, the auditor nevertheless displays concern for how he/she is perceived by the auditees. Satisfying their need for reassurance ultimately serves the IAF's goal of attaining information from them.

During the audit engagement, according to the IIA's standard 2300 - Performing the Engagement, auditors have to "identify, analyze, evaluate, and document sufficient information to achieve the engagement's objectives". The obtained data needs to be "reliable, relevant, and useful". To obtain reliable information it is important that auditors use appropriate techniques, which can include specific interview tactics as well as the involvement of external support. Often, such third-party involvement will be decided during engagement planning, when it becomes apparent that there might be timing issues or a lack of relevant competencies in the audit team. At other times, circumstances or unforeseen complication on-site might make it necessary to acquire external support. 
When interviewing employees or management of a foreign entity, the auditors are seeking resources in the form of information. Obtaining it is a balancing act between being courteous and respectful of local characteristics on the one hand and being assertive enough to uncover truthful and complete information from possibly unwilling auditees on the other hand. Interviews are a critical part of the audit work and often create conflict situations due to the opposing goals of the involved parties. The auditors' goal is to receive crucial information while the auditees' goal might simply be to avoid negative audit findings.

Competing: "It is a game and whoever thinks that he is never being lied to because it's all so nice and cordial, he is also wrongly advised. The audited entities are trying to fool you on a daily basis. They will sometimes not tell you things or give you incorrect answers. So, this is the normal interplay, think ... it is interplay of harmonious cooperation, sportsmanlike ambition and therefore sometimes not telling the whole story, and sometimes also being a little scared." (10A)

The opposing goals can lead both parties to compete with each other. Auditees can act assertive and uncooperative if they are determined not to give out relevant information. Auditors must be aware that auditees will sometimes lie in order to achieve their objective and might even see the audit as a challenge or game where the audited entity is pitted against the IAF. Obtaining the necessary resources from the auditees can, therefore, be quite complicated. The interplay between collaboration and competition adds to the challenge the IAF is facing since auditors will first have to determine which conflict-handling mode the auditees are employing. In such situations, culture or countryspecific characteristics can further complicate the ambiguous auditor-auditee relationship and impede the IAF's goal of providing comprehensive assurance.

Competing: "Anyways, I mean if the Greeks say 'it is different for us' there are two rules. First, you have to really let them explain and justify why something is different and not just accept it. That's first. Maybe also ask them about the legal foundations. 'Show me!'” (03B)

Since auditees might give answers that are ambiguous, incomplete or incorrect auditors are skeptical of the information they receive and try to verify or to obtain more details. Through this back and forth of asking a question, receiving an answer, asking a follow-up question or requesting additional data, etc., the auditor tries to enforce his right to complete information and his obligation to be thorough. Auditors also seem aware that national and cultural characteristics to some extent shape the auditees' behavior during the interviews.

Competing: "I spent a long time in India and there a question will always be answered with 'yes'. And this means that you have to approach it with a whole different method if you want answers about how it really works because they will always try to tell you what you want to hear, so they will try to figure out 'what do you want to hear?' And then they will try to sell it to you, I would say. And this obviously makes the audit a little more difficult, time will be tighter than maybe in other countries because you always have this cultural component ... I'll say, play with it, let them talk more and ask fewer questions, because then they obviously can't really guess where I want to go with my question." (04B)

This statement demonstrates the importance of cultural knowledge which allows auditors to adjust their audit approach and interview techniques to achieve the desired result. It is interesting to observe the swiftness with which this auditor uses their personal experience of living in India to generalize from the behavior of Indian locals to the behavior of Chinese auditees. However, it does not seem counterintuitive that the cultural differences between Germany and various Asian countries are perceived much more strongly than differences among the respective Asian cultures. While providing the auditees with as little information as possible in order not to influence their responses seems like a general interview tactic this auditor uses in Asian countries, another auditor mentions a riskier and less universally applicable method:

Competing: "Well, and sometimes you have to bluff a little bit. ... I happen to know what our company name looks like in Chinese characters. And during an audit on-site in China, the issue was who had registered our company back in the days, something like that. And there was an official document laying on the table which my counterpart didn't want to show to me or didn't want to give to me and he completely ignored it and I saw that our [company] name was on it. And I said 'that there is the document, give that to me!' and I simply bluffed and I was spot on." (06A)

Both auditor and auditee are being assertive and uncooperative. The auditor is set on obtaining a specific document while the auditee is determined to prevent the auditor from receiving certain information. By using Chinese language skills, even though they are actually very limited, in combination with what the auditor called a lucky guess, the impression is conveyed that the auditee cannot hide information from the auditors simply because documents are written in Chinese characters. The above examples illustrate how crucial linguistic and cultural knowledge can be for the success of a specific audit engagement when trying to gain assistance and obtain necessary resources from auditees. Not only are they sometimes the only way to ensure the auditor receives all relevant information, but country and culture-specific knowledge will also enable the IAF to save precious time during the on-site engagement and thus serve a temporal resource goal.

Collaborating: "[In Vietnam] we spent half an hour discussing why you would rent a company car and not lease it, because leasing should be cheaper. And it took more than half an hour until we understood that there you rent a car because then the driver is included because none of the local engineers could afford a driver's license." (06B)

Conflict situations like the one auditors encountered in Vietnam illustrate the danger of taking a concept or condition from one's native country, presuming that it is a universally valid norm and applying it to other countries and cultures without questioning its applicability. A lack of local knowledge may thus obstruct the process of obtaining information even if both parties are collaborating by trying to understand each other and finding the best solution for everyone involved. In order to obtain informational resources, precious time is wasted. However, counterexamples, where 
the auditor is aware of local regulations as well as the resulting conditions and mindsets on-site, were also reported.

Compromising: "In Greece for example, there isn't even such a law [for protecting minors], so I have to do the audit differently. I could set very high standards, but at the end of the day you need to be careful that you're not doing things culturally which will unsettle everyone if you were to constantly ask people: ‘are you already 18 years old?'” (10A)

The auditor aims to be culturally sensitive and to avoid unsettling the auditees which would impair the auditor-auditee relationship. Auditors might have to compromise and adjust the audit accordingly. However, the audit is still being conducted, albeit in a different manner or following a different approach. While compliance with national laws and regulations is obligatory, exceptions to the company policy might be granted to certain foreign entities. However, such special arrangements might look suspicious to a German auditor who is unfamiliar with the reasoning behind the exception.

Competing: "Normally, we have this policy: there are no company credit cards. But the Koreans argued 'for us hospitality expenses are only tax deductible if they can be proven to have been paid with a credit card'. At first, we didn't believe this, but in the end, the external auditors confirmed this also with the legal text so that we could check for ourselves." (03B)

In the above case, auditors did not believe the information they received from the auditees and an objective external party with local expertise is needed to resolve the conflict. While the main goal of obtaining relevant information to effectively provide assurance is achieved, calling on external experts only once internal auditors and auditees have reached an impasse can be costly in regards to monetary and temporal resources.

Many IAFs will recruit a third party such as external auditors, interpreters or guest auditors from operational entities inside the company to support the audit team on-site from the beginning, which may prevent conflicts due to language barriers, misunderstandings, or trust issues. Apart from providing additional assurance, external auditors recruited from a local auditing firm will have extensive knowledge of local rules and regulations and will also be familiar with the local culture and language, all of which can help to achieve the goal of obtaining necessary information regardless of an oftentimes tight timeframe. Many IAFs will include an external party on a foreign audit assignment to compensate for their auditors' lack of country-specific knowledge. They are aware that missing cultural or language skills can cause unnecessary conflicts and be just as grave of an impediment to a successful audit as a lack of technical expertise. Thus, it is important that auditors are knowledgeable and that the IAF has the resources available to compensate for any potential deficits in skills or expertise through, e.g., external support. As one auditor points out:

Compromising: "Well, you need to be accepted on-site because of your competence and if you want to force acceptance through the hierarchy, and this is the challenge especially for auditors abroad, it will go wrong. You might get lucky one or two times, but you always meet twice in life and with a small IAF you will meet three, four, five, ten times." (06A)
The IAF, even if they occupy a distinct position within the company, cannot rely on their affiliation to the company's management or headquarters to solve conflicts. Being assertive and uncooperative and using hierarchy to enforce their right to information, might seem like the easiest solution in the short term. However, to be successful in the long term, auditors need to compromise to achieve their resource-related goals.

\subsection{Post-audit reporting}

The IIA's standard 2400 - Communicating Results, states that when auditors communicate the results of engagements, their "communications must be accurate, objective, clear, concise, constructive, complete, and timely". This means auditors need to ensure that the information they convey and the way in which they communicate is helpful to the audited entity and provides them with all relevant information to enable them to make necessary improvements. Apart from the specific content of an audit report, the timing of its release is also an important factor that bears the potential for conflict and to negatively influence the auditor-auditee relationship if it is not managed carefully.

Compromising: "The entire audit report first goes to the audited entity .... The aim is to have the flow of information clearly regulated from the bottom up. ... then, when everything is ready, my boss [the CAE] will bring the report to the company's executive board ... And this is, well, we try to strictly stick to this, because we as the centralized IAF are not per se and per definition seen as friends of the local entities." (06A)

This auditor is aware of the potentially complicated relationship between the IAF and foreign entities and a special effort is made to compromise and address the auditees' needs by including them in the reporting process early. Allowing them to familiarize themselves with the audit findings and prepare for questions or comments the executive board might later address to them, aims to positively influence the auditees' view of the IAF and establish trust. Another IAF not only informs the audited entity early in the process but even gives them the opportunity to influence the wording of the report:

Compromising: "[After the audit] we would go back to [the head audit office in] Germany and do a first draft of the audit report with the corresponding findings. We would check those in the department, do quality control and then send the report to the management that we audited who will then proofread the whole thing, create nuances which from their point of view are to be evaluated differently.... The report will be finalized and distributed to the target audience only once we and the [audited entity] come to an understanding." (08A)

By granting the audited entity the possibility to alter the report's wording the IAF positions itself as a partner and demonstrates that the auditee's opinions are valid and will be respected. The IAF aims to establish a relationship that fosters partnership and cooperation with the audited entity by sending out the report only after a compromise and agreement between both parties is reached.

Regardless of the timing of the audit report release, one auditor reported a general difference 
between how audit findings are received domestically and abroad:

Collaborating: "Especially [outside of Germany] criticism is basically received positively. Often they see it as a form of improvement that they hadn't thought about before, where they maybe didn't always get all the information from the group and especially in foreign countries it's really like, they are sometimes very happy that we were there, even if we had many negative findings, but in the long run it is an improvement for them when you address these negative findings." (06B)

In the auditor's opinion, most auditees are happy to collaborate with the IAF and to implement suggested measures. Here it seems that the audited entity is benefitting from the information and resources provided by the IAF. However, it is unclear whether the perceived difference between German and non-German auditees' attitudes can be ascribed to the fact that auditors from the company's German headquarters and their judgements are valued more highly abroad or whether cultural differences are at play which specifically causes German auditees to react more negatively to criticism.

While auditors are doing their assessments, the auditees are inevitably also seizing up the auditors, which bears a certain potential for conflict:

Avoiding: "If I receive a phone call from someone [from a foreign country] or also here from the international team - not the IAF - but from an audited international specialist department and they say 'I did not really agree here' then it almost always goes back to ... the person not having the necessary expertise, interpreting things incorrectly, asking questions unskillfully, not being at home within a certain field." (10A)

However, rather than entering into a conflict situation, auditees might avoid a direct in-person confrontation. Auditees may still communicate their dissatisfaction with an auditor's performance but do so after the auditors have left the site. This uncooperative and unassertive behavior might simply result in the postponement of the conflict as described in the situation above where auditees avoid a conflict situation with the auditors on-site, but later take up a discussion with the CAE. Such concerns should be taken seriously by the IAF regardless in order to foster a positive auditorauditee relationship. A department whose job it is to find weaknesses and suggest improvements would, after all, do well to be open to constructive criticism itself if it wants to maintain its credibility.

\section{DISCUSSION AND CONCLUSION}

The purpose of this study is to provide insight into the conflict-handling styles of internal auditors and auditees in an international context. The strength of the qualitative method employed lies in its ability to capture the insiders' experiences of how they behave during international audit engagements, how they interact with auditees of a different national and cultural background and how they handle challenges that arise because of the differing job profiles and cultural backgrounds of both parties. Five conflicthandling modes according to Thomas and Kilmann (1974) were used to structure and describe the interactions between internal auditors and auditees during the various stages of the audit engagement.
Applying RDT is found to be helpful in explaining the conflict-handling styles which are employed.

The IAF, like other departments and organizations, is being influenced by its surroundings and by being to some extent reliant on resources from the audited entity can help to explain the decisions and behavior of internal auditors. In addition to striving to gain assistance in the form of information, conflicts are often handled with relational resource goals in mind and auditors are keen to establish and maintain a trustful and positive relationship with auditees. In accordance with RDT, the IAF will also try to reduce uncertainties that are related to being resource dependent by restructuring these dependencies. Strategies can include acquiring information from alternative sources such as external auditors, interpreters or guest auditors or establishing interorganizational arrangements, so-called interlocks, e.g. with expatriates on-site. This paper also finds that a strong corporate culture and a shared sense of solidarity between auditors and auditees enormously facilitate audit engagements and the obtainment of informational resources across cultural and national borders.

Most audits constitute situations where two parties with opposing or diverging interests come into conflict. Conflicts are handled by competing, collaborating, compromising, avoiding or accommodating. The five conflict-handling styles are employed more or less frequently and for a variety of different reasons. While auditees will sometimes use avoiding to sidestep any potential conflict, perhaps unsurprisingly, internal auditors, in general, do not employ this approach to conflicts. This finding is in line with the core principles of auditors having to be proactive and demonstrating due professional care as well as with the assumption that the IAF is reliant on certain resources from the audited entity. Auditors must be aware that each audit harbors the potential for conflict and must be willing to actively handle such situations to achieve their goals. This is especially true in the context of cross-national audits, where the time on-site is limited and the option to conduct the necessary testing or interviews at a later date does not exist. Competing takes place most often during face to face interactions in the context of interviews on site. Auditees will at times aim to hide information or tailor their statements to what they think an auditor wants to hear. Auditors, on the other hand, are understandably skeptical of the information provided and will employ a variety of tactics, such as giving out minimal information themselves or demanding evidence, to achieve their goals and receive all necessary informational resources. In comparison, collaboration happens due to a strong sense of unity within the company and a positive or even trustful relationship between auditor and auditees. This is a significant accomplishment considering geographical distances and language barriers in multinational firms. Due to these national differences, collaboration is very much needed during international audit engagements since auditors are partly reliant on auditees to work with them to solve any misunderstandings or clear up false assumptions regarding the audit matter. Auditors sometimes employ compromising as a conflict-handling strategy, e.g., when adjusting an audit to country-specific regulations, or allowing the 
audited entity to provide input on the wording of the audit report. However, while auditors might be willing to compromise, this strategy is mostly applied to non-essential parts of the audit that will not affect the end result. Auditors that make substantial concessions to the audited entities would no longer be considered free from undue influence and thus fully independent in accordance with the IIA's core principles, which is also why auditors use accommodating only in regards to staffing decisions during the audit preparation phase. The IAF is mindful of which person is sent and in what role. However, such accommodating behavior is only possible in audit functions that have a pool of auditors that are equally qualified for a certain assignment. Only once multiple auditors can be chosen based on suitable skills and knowledge, other factors such as gender or nationality should be considered.

The significance of aspects like reliability and predictability are stressed by the interviewed auditors and conflict-handling styles that allow for the establishment of positive relationships play a prominent role in auditor-auditee interactions. Without a certain basis of trust, the open discussion of sensitive or critical topics would hardly be possible (Schäfer, 2009). This trusting relationship is often knowledge-based, which means that it is built on information, predictability, and reliability (Shapiro et al., 1992). In order to maintain or encourage such trust in the IAF, auditors need to follow a consistent and credible information policy (Schweer \& Thies, 2003). Findings illustrate the importance of cooperative behavior and a constant stream of information during every phase of the audit engagement. If the auditors' actions are cooperative and transparent, auditees are more likely to accept the internal audit work even if it entails potential costs or other disadvantages for them (Lewicki \& Bunker, 1996). Additionally, this study shows that even though auditors are partly reliant on the auditees' knowledge and willingness to cooperate, auditors remain the more powerful party. This can be due to various factors such as the auditors' direct connection to the company's headquarters, a functioning cross-corporate network, extensive experience in working with people from different countries, and their right to information, which the IIA suggests to implement in the Internal Audit Charter and which auditors exercise by demanding evidence and conducting interviews until they receive satisfactory results.

The predominant view among interviewed auditors is that the IAF always manages to obtain the necessary information from an audited entity. How this resource goal is achieved varies widely and depends on the specific context. Misunderstandings are sometimes inevitable and can easily evolve into a conflict situation, caused by the parties' differing cultural and national backgrounds and their respective expectations of normalcy. On the other hand, some auditees seem unwilling to cooperate and be truthful with the IAF and tense situations might arise simply due to an audit taking place and without much connection to cultural or linguistic barriers. However, such barriers have the potential to further complicate the ongoing conflict. Auditors, therefore, need to be able to question their own knowledge and assumptions and be willing to listen to the auditees' concerns. On the other hand, they must be assertive and skeptical since they cannot simply accept every explanation given by an auditee. A delicate balance needs to be found and adjusted for each new audit assignment, taking into consideration the circumstances in each specific country and of every individual auditee as well as the IAF's resource requirements.

\subsection{Limitations}

Notwithstanding the precautions that were taken, there are certain limitations to this study to be aware of. First, since only auditors were interviewed for this study, the foreign audited entities are observed and their behavior is analyzed from the auditor's perspective. Because the staff and managers of audited entities did not have the opportunity to voice their experiences and opinions, this study does not claim to represent a complete picture of the auditor-auditee relationship.

Secondly, a potential self-selection bias needs to be addressed. It is possible that only auditors who are not worried about their performance during international audit assignments agreed to be interviewed. Auditors, who struggle or are unable to successfully complete audits in an international setting, could be embarrassed and therefore unwilling to talk about their experiences. However, participants did not try to hide or explain away the arising conflict situations and many freely admitted to needing third-party support. Furthermore, a number of this study's participants are voluntary members of a national IIA committee investing time and effort into the investigation of the topic area of internal auditing in an international environment. This suggests that the respective IAFs have identified internationality as an important factor that influences and challenges internal auditing and represents a potential problem area with room for improvement.

Another concern is the possibility that interviewees could respond normatively to the interview questions. Because some of the interviewed auditors hold executive positions, e.g., $\mathrm{CAE}$, the concern is that they aim to represent their IAF, themselves and their employees in a positive light and would therefore not talk about the troubles they face when auditing internationally or make them seem more insignificant than they actually were. However, the candid interviews that were conducted suggest that this is not a problem for this study and that the auditors were honest with the interviewer, as many of them reported difficulties and a lack of local knowledge for which they sought help from third parties. In the same vein, this openness points to the conclusion that subordinates' perception of psychological safety (Kahn, 1990) during interviews conducted with two interviewees pertaining to different hierarchical levels, did not impede their willingness to communicate honest opinions and experiences.

\subsection{Implications and future research}

That knowledge about human behavior will continue to increase in importance because of the greater complexity of business processes is a sentiment Blakeney et al. (1976) expressed decades ago and which remains true today. Because of ongoing globalization and internationalization of the 
business environment and the subsequently increasing contact of people from different cultures, this statement has not lost any of its relevance. The creation and maintenance of long-term, strategic relationships in a global working environment requires getting to know, understanding, and valuing the habits and behaviors of different nationalities and cultures. Successful communication and handling of conflicts will play an increasingly important role for the relationships between the IAF and the audited entities all over the world which makes communication skills a continually crucial factor in determining the IAF's value contribution to its organization.

The identification of differences in thinking, perceiving, acting and communicating makes it possible to take measures to avoid or remove disruptions caused by country or culture-specific characteristics (Dülfer \& Jöstingmeier, 2008) and to handle conflicts in a productive manner. This process requires the development of a distinct cultural sensitivity and strong interpersonal communication skills which should be of special relevance to students and recent graduates hoping to pursue a career in internal auditing. This study further highlights the need for internal audit practitioners to find the right balance between being unassuming and open to what auditees have to say, while at the same time applying professional skepticism. Being knowledgeable or able to secure informational resources about country-specific circumstances is a prerequisite to obtaining necessary resources from auditees. The finding that a strong and cohesive corporate culture can greatly facilitate the internal auditors' work abroad has implications for company management as it presents an incentive to actively encourage and shape the formation of a globally shared organizational mindset.

This study also has implications for researchers since it provides a number of future research opportunities. Further insight into the relationship between internal auditors and auditees of different cultural backgrounds could be provided through in-depth interviews with auditees. Analyzing their experiences would serve to deepen the present understanding of auditor-auditee interactions during international audit assignments. This would also serve to check whether auditors' self-perception aligns with how they and their behavior are perceived by the auditees. Future studies could also examine the role of age and gender diversity in this context. Moreover, the interactions between auditors from the main audit office and auditors of the same function's regional audit offices need to be explored in order to provide a holistic view on the relationships that govern internal auditing in the international context.

\section{REFERENCES}

1. Allen, R. D. (1996). Managing internal audit conflicts. Internal Auditor, 53(4), 58-61. Retrieved from http://search.ebscohost.com/login.aspx?direct=true\&AuthType=ip,uid\&db=buh\&AN=9608224522\&site=ehostlive\&scope $=$ site

2. Anderson, U. (2003). Assurance and consulting services. Florida, USA: Altamonte Springs, The Institute of Internal Auditors Research Foundation. Retrieved from https://global.theiia.org/iiarf/Public\%20Documents/ Chapter\%204\%20Assurance\%20and\%20Consulting\%20Services.pdf

3. Archambeault, D. S., DeZoort, F. T., \& Holt, T. P. (2008). The need for an internal auditor report to external stakeholders to improve governance transparency. Accounting Horizons, 22(4), 375-388. https://doi.org/ 10.2308/acch.2008.22.4.375

4. Barrett, M., Cooper, D., \& Jamal, K. (2005). Globalization and the coordination of work in multinational audits. Accounting, Organizations and Society, 30(1), 1-24. https://doi.org/10.1016/j.aos.2004.02.002

5. Bart, C., \& McQueen, G. (2013). Why women make better directors. International Journal of Business Governance and Ethics, 8(1), 93-99. https://doi.org/10.1504/IJBGE.2013.052743

6. Beasley, M. S., Carcello, J. V., Hermanson, D. R., \& Neal, T. L. (2009). The audit committee oversight process. Contemporary Accounting Research, 26(1), 65-122. https://doi.org/10.1506/car.26.1.3

7. Blake, R. R., \& Mouton, J. S. (1964). The managerial grid. Houston: Gulf Publishing Co.

8. Blakeney, R. N., Holland, W. E., \& Matteson, M. T. (1976). The auditor-auditee relationship: Some behavioral considerations and implications for auditing education. The Accounting Review, 51(4), 899-906. Retrieved from https://www.jstor.org/stable/246137

9. Boxenbaum, E., \& Rouleau, L. (2011). New knowledge products as bricolage: Metaphors and scripts in organizational theory. The Academy of Management Review, 36(2), 272-296. https://doi.org/10.5465/ AMR.2011.59330898

10. Burt, I. (2016). An understanding of the differences between internal and external auditors in obtaining information about internal control weaknesses. Journal of Management Accounting Research, 28(3), 83-99. https://doi.org/10.2308/jmar-51471

11. Burton, F. G., Emmett, S. A., Simon, C., \& Wood, D. A. (2012). Corporate managers' reliance on internal auditor recommendations. Auditing: A Journal of Practice \& Theory, 31(2), 151-166. https://doi.org/10.2308/ajpt-10234

12. Chambers, A. (2008). The board's black hole - filling their assurance vacuum: Can internal audit rise to the challenge? Measuring Business Excellence, 12(1), 47-63. https://doi.org/10.1108/13683040810864387

13. Choi, J. H., Kim, C., Kim, J. B., \& Zang, Y. (2010). Audit office size, audit quality, and audit pricing. Auditing: A Journal of Practice \& Theory, 29(1), 73-97. https://doi.org/10.2308/aud.2010.29.1.73

14. Cohen, J. R., Krishnamoorthy, G., \& Wright A. M. (2008). Form versus substance: The implications for auditing practice and research of alternative perspectives on corporate governance. Auditing: A Journal of Practice \& Theory, 27(2), 181-198. https://doi.org/10.2308/aud.2008.27.2.181

15. Cohen, J., Krishnamoorthy, G., \& Wright, A. (2010). Corporate governance in the post-Sarbanes-Oxley era: Auditors' experiences. Contemporary Accounting Research, 27(3), 751-786. https://doi.org/10.1111/j.19113846.2010.01026.x

16. Dillard, J. P., Segrin, C., \& Harden, J. M. (1989). Primary and secondary goals in the production of interpersonal influence messages. Communication Monographs, 56(1), 19-38. https://doi.org/10.1080/03637758909390247

17. Dittenhofer, M. A. (2001). Internal auditing effectiveness: An expansion of present methods. Managerial Auditing Journal, 16(8), 443-450. https://doi.org/10.1108/EUM0000000006064

$$
\text { VIRTUS }
$$


18. Dittenhofer, M. A., Ramamoorti, S., Ziegenfuss, D. E., \& Evans, R. L. (2010). Behavioral dimensions of internal auditing: A practical guide to professional relationships in internal auditing. Florida, USA: Altamonte Springs, The Institute of Internal Auditors Research Foundation. Retrieved from https://www.interniaudit.cz/download/ Publikace-IIA/5015.2.dl-Behaviorial\%20Dimensions-Survey\%20report-FINAL_copy\%20for\%20web\%20zip.pdf

19. D’Onza, G., \& Sarens, G. (2018). Factors that enhance the quality of the relationships between internal auditors and auditees: Evidence from Italian companies. International Journal of Auditing, 22(1), 1-12. https://doi.org/10.1111/ijau.12100

20. Dülfer, E., \& Jöstingmeier, B. (2008). Internationales Management in unterschiedlichen Kulturbereichen (7th ed.). München: De Gruyter Oldenbourg.

21. Edgell, S. (1980). Middle-class couples: A study of segregation, domination and inequality in marriage. London: George Allen and Unwin. https://doi.org/10.1177/144078338201800320

22. Elliott, M., Dawson, R., \& Edwards, J. (2007). An improved process model for internal auditing. Managerial Auditing Journal, 22(6), 552-565. https://doi.org/10.1108/02686900710759370

23. Fanning, K., \& Piercey, M. D. (2014). Internal auditors' use of interpersonal likability, arguments, and accounting information in a corporate governance setting. Accounting, Organizations and Society, 39(8), 575-589. https://doi.org/10.1016/j.aos.2014.07.002

24. Folger, J. P., \& Poole, M. S. (1984). Working through conflict: A communication perspective. Glenview, IL: Scott, Foresman.

25. Funnell, W., \& Wade, M. (2012). Negotiating the credibility of performance auditing. Critical Perspectives on Accounting, 23(6), 434-450. https://doi.org/10.1016/j.cpa.2012.04.005

26. Gendron, Y. (2013). (Re)thinking the academic contribution. Comptabilité Contrôl Audit, 19(2), 135-155. https://doi.org/10.3917/cca.192.0133

27. Guest, G., Bunce, A., \& Johnson, L. (2006). How many interviews are enough? An experiment with data saturation and variability. Field Methods, 18(1), 59-82. https://doi.org/10.1177/1525822X05279903

28. Guénin-Paracini, H., Malsch, B., \& Tremblay, M.-S. (2015). On the operational reality of auditors' independence: Lessons from the field. Auditing: A Journal of Practice \& Theory, 34(2), 201-236. https://doi.org/10.2308/ajpt50905

29. Hirst, D. E., \& Koonce, L. (1996). Audit analytical procedures: A field investigation. Contemporary Accounting Research, 13(2), 457-486. https://doi.org/10.1111/j.1911-3846.1996.tb00511.x

30. Hofstede, G. (2001). Cultures consequences: Comparing values, behaviors, institutions, and organizations across nations (2nd ed.). Thousand Oaks, CA: Sage Publications. https://digitalcommons.usu.edu/unf_research/53/

31. House, R. J. (2004). Introduction. In R. J. House, P. J. Hanges, M. Javidan, P. W. Dorfman, \& V. Gupta (Eds.), Culture, leadership, and organizations: The globe study of 62 societies (pp. 1-3). Thousand Oaks, CA: Sage Publications.

32. IIA (2008). Model internal audit activity charter. Retrieved from https://global.theiia.org/standardsguidance/public\%20documents/modelcharter.pdf

33. IIA (2016). The international professional practices framework. Retrieved from https://na.theiia.org/standardsguidance/Pages/Standards-and-Guidance-IPPF.aspx

34. Kahn, W. A. (1990). Psychological conditions of personal engagement and disengagement at work. Academy of Management Journal, 33(4), 692-724. https://doi.org/10.5465/256287

35. Larkin, J. M. (2000). The ability of internal auditors to identify ethical dilemmas. Journal of Business Ethics, 23(4), 401-409. https://doi.org/10.1023/A:1006150718834

36. Lenz, R., \& Hahn, U. (2015). A synthesis of empirical internal audit effectiveness literature pointing to new research opportunities. Managerial Auditing Journal, 30(1), 5-33. https://doi.org/10.1108/MAJ-08-2014-1072

37. Lenz, R., Sarens, G. \& Hoos, F. (2017). Internal audit effectiveness: Multiple Case study research involving chief audit executives and senior management. The EDP Audit, Control and Security Newsletter, 55(1), 1-17. https://doi.org/10.1080/07366981.2017.1278980

38. Lewicki, R. J., \& Bunker, B. B. (1996). Developing and maintaining trust in work relationships. In R. M. Kramer \& T. R. Tyler (Eds.), Trust in organizations: Frontiers of theory and research (pp. 114-139). Thousand Oaks, CA: Sage Publications. https://doi.org/10.4135/9781452243610.n7

39. Lincoln, Y., \& Guba, E. G. (1985). Naturalistic inquiry. Thousand Oaks, CA: Sage Publications.

40. Lincoln, Y. S., Lynham, S., \& Guba, E. G. (2011). Paradigmatic controversies, contradictions, and emerging confluences. In N. K. Denzin \& Y. S. Lincoln (Eds.), The Sage handbook of qualitative research (pp. 97-128), (4th ed.). Thousand Oaks, CA: Sage Publications. Retrieved from https://www.worldcat.org/title/sagehandbook-of-qualitative-research/oclc/681497827

41. Loss, J. (2000). The communication contract. Internal Auditor, 57(6), p. 88.

42. Lüsebrink, H. J. (2012). Interkulturelle Kommunikation: Interaktion, Fremdwahrnehmnung, Kulturtransfer (3rd ed.). J. B. Metzler, Stuttgart. https://doi.org/10.1007/978-3-476-00795-7

43. Ma'ayan, Y. \& Carmeli, A. (2016). Internal audits as a source of ethical behavior, efficiency, and effectiveness in work units. Journal of Business Ethics, 137(2), 347-363. https://doi.org/10.1007/s10551-015-2561-0

44. Malsch, B., \& Salterio, S. E. (2016). Doing good field research: Assessing the quality of audit field research. Auditing: A Journal of Practice \& Theory, 35(1), 1-22. https://doi.org/10.2308/ajpt-51170

45. Mayring, P. (2000). Qualitative content analysis. Forum: Qualitative Social Research, 1(2), 1-10. Retrieved from http://www.qualitative-research.net/index.php/fqs/article/download/1089/2386

46. Mayring, P. (2014). Qualitative content analysis: Theoretical foundation, basic procedures and software solution. Retrieved from https://www.ssoar.info/ssoar/handle/document/39517

47. McGrath, J. E. (1984). Groups: Interaction and performance. Englewood Cliffs, NJ: Prentice-Hall. Retrieved from https://trove.nla.gov.au/work/26917239?q\&versionId=45010419

48. Mints, F. E. (1972). Behavioral patterns in internal audit relationships (Research Committee Report No. 17). New York: The Institute of Internal Auditors.

49. O'Dwyer, B. (2011). The case of sustainability assurance: Constructing a new assurance service. Contemporary Accounting Research, 28(4), 1230-1266. https://doi.org/10.1111/j.1911-3846.2011.01108.x

50. Patton, M. W. (1990). Oualitative evaluation and research methods (2nd ed.). Newbury Park, CA: Sage Publications. 
51. Pfeffer, J., \& Salancik, G. (1978). The external control of organizations. A Resource dependence perspective. New York: Harper \& Row. Retrieved from https://www.gsb.stanford.edu/faculty-research/books/external-controlorganizations-resource-dependence-perspective

52. Pickett, K. H. S. (2007). The essential handbook of internal auditing. Chichester, West Sussex: John Wiley and Sons Ltd. Retrieved from https://ahmadladhani.files.wordpress.com/2008/12/the-essential-handbook-ofinternal-auditing.pdf

53. Pickett, K. H. S. (2010). The internal auditing handbook (3rd ed.). Chichester, West Sussex: John Wiley and Sons Ltd. Retrieved from https://rdhsak.files.wordpress.com/2016/04/k-h-spencer-pickett-the-internal-auditinghandbook-wiley-2010-ori.pdf

54. Power, M. K., \& Gendron, Y. (2015). Qualitative research in auditing: A methodological roadmap. Auditing: A Journal of Practice \& Theory, 34(2), 147-165. https://doi.org/10.2308/ajpt-10423

55. Prawitt, D. F., Smith, J. L., \& Wood, D. A. (2009). Internal audit quality and earnings management. The Accounting Review, 84(4), 1255-1280. https://doi.org/10.2308/accr.2009.84.4.1255

56. Rahim, M. A. (1992). Managing conflict in organizations (2nd ed.). Praeger, Westport, CT.

57. Rahim, A., \& Bonoma, T. V. (1979). Managing organizational conflict: A model for diagnosis and intervention. Psychological Reports, 44(3), 1323-1344. https://doi.org/10.2466/pr0.1979.44.3c.1323

58. Reynolds, M. A. (2000). Professionalism, ethical codes and the internal auditor: A moral argument. Journal of Business Ethics, 24(2), 115-124. https://doi.org/10.1023/A:1006179723979

59. Roussy, M. (2013). Internal auditors' roles: From watchdogs to helpers and protectors of the top manager. Critical Perspectives on Accounting, 24(7-8), 550-571. https://doi.org/10.1016/j.cpa.2013.08.004

60. Roussy, M. (2015). Welcome to the day-to-day of internal auditors: How do they cope with conflicts? Auditing: A Journal of Practice \& Theory, 34(2), 237-264. https://doi.org/10.2308/ajpt-50904

61. Schäfer, F. (2009). Erfolgreiche Kooperation in Unternehmen: Warum wir heute mehr brauchen als gute Führungskräfte. Frankfurt-am-Main: Campus.

62. Schein, E. H. (2010). Organisationskultur. Bergisch Gladbach: Edition Humanistische Psychologie.

63. Schweer, M., \& Thies, B. (2003). Vertrauen als Organisationsprinzip: Perspektiven für komplexe Systeme. Bern: Hans Huber. Retrieved from https://d-nb.info/967116147/04

64. Seymour, J., Dix, G., \& Eardley, T. (1995). Joint accounts: Methodology and practice in research interviews with couples. York, England: University of York Social Policy Research Unit.

65. Shapiro, D. L., Sheppard, B. H., \& Cheraskin, L. (1992). Business on a handshake. Negotiation Journal, 8(4), 365377. https://doi.org/10.1111/j.1571-9979.1992.tb00679.x

66. Skinner, D., \& Spira, L. F. (2003). Trust and control - a symbiotic relationship? Corporate Governance: The International Journal of Business in Society, 3(4), 28-35. https://doi.org/10.1108/14720700310497096

67. Smith, G. (2005). Communication skills are critical for internal auditors. Managerial Auditing Journal, 20(5), 513-519. https://doi.org/10.1108/02686900510598858

68. Sweeney, B., \& Pierce, B. (2011). Audit team defense mechanisms: Auditee influence. Accounting and Business Research, 41(4), 333-356. https://doi.org/10.1080/00014788.2011.559575

69. Thomas, K. W., \& Kilmann, R. H. (1974). The Thomas-Kilmann conflict mode instrument. New York: Tuxedo. https://doi.org/10.1037/t02326-000

70. Thomas, K. W., \& Kilmann, R. H. (2008). Thomas-Kilmann conflict mode instrument: Profile and interpretive report. Retrieved from http://www.kilmanndiagnostics.com/sites/default/files/TKI_Sample_Report.pdf.

71. Watzlawick, P., Beavin, J. H. \& Jackson, D. D. (1967). Pragmatics of human communication: A study of interactional patterns, pathologies, and paradoxes. New York: Norton. Retrieved from https://trove.nla.gov.au/ work/10678905

72. Wealleans, D. (2005). The quality audit for ISO 9001:2000: A practical guide. London: Gower. https://doi.org/ $10.4324 / 9781315237534$

73. Woodworth, B. M., \& Said, K. E. (1996). Internal auditing in a multicultural environment: The Saudi Arabia experience. Managerial Auditing Journal, 11(2), 20-27. https://doi.org/10.1108/02686909610107942 


\section{Conflict-handling during multinational audits}

Krane, Ronja

This text is provided by DuEPublico, the central repository of the University Duisburg-Essen. This version of the e-publication may differ from a potential published print or online version.

DOI: https://doi.org/10.22495/cocv16i3art13

URN: urn:nbn:de:hbz:464-20190619-100517-1

Link: https://duepublico.uni-duisburg-essen.de:443/servlets/DocumentServlet?id=48940

License:

(cC) (i)

This work may be used under a Creative Commons Attribution 4.0 International license.

Source: Corporate Ownership \& Control, 16(3), 159-173 (2019); Published online: 12.06.2019 